\title{
Wear Properties of Surface Modified Hard Layers Using Electrical Discharge Machine*
}

\author{
Koei MATSUKAWA $^{* *}$, Katsunori SATOH ${ }^{* * *}$, Akihiro GOTO ${ }^{* * * *}$, \\ Nagao SAITO $^{* * * * *}$ and Naotake MOHRI ${ }^{* *}$ \\ **Advanced Technology R\&D Center, Mitsubishi Electric Corporation, \\ 8-1-1, Tsukaguchi-honmachi, Amagasaki, 661-8661, Japan \\ E-mail: Matsukawa.Koei@cs.MitsubishiElectric.co.jp \\ ***Mitsubishi Electric Engineering Company Limited, \\ 6-16-1,Tsukaguchi-honmachi, Amagasaki, 661-0001, Japan \\ E-mail: Sato.Katsunori@zc.MitsubishiElectric.co.jp \\ ****Nagoya Works, Mitsubishi Electric Corporation, \\ 5-1-14,Yada-minami, Higashi-ku, Nagoya, 461-8670, Japan \\ E-mail: Goto.Akihiro@ap.MitsubishiElectric.co.jp \\ **** $\mathrm{S} \cdot \mathrm{N}$ Engineering Laboratory, \\ 9-12-12, Iwanaridai, Kasugai, 487-0033, Japan \\ ****** Graduate School of Engineering, The University of Tokyo \\ 7-3-1, Hongo, Bunkyo-ku, Tokyo, 113-8656, Japan \\ E-mail: nmohri@cim.pe.u-tokyo.ac.jp
}

\begin{abstract}
Recently hard layers have tried to be formed using electrical discharge machines (EDMs) which are mainly used now for material removal. The time and cost of producing dies and machine parts can be greatly reduced when the same EDM is used as the main plant machine in die making and surface modification. The wear properties of hard layers formed on stainless steel using EDM were studied. As a result, it was found that surface layers modified with both titanium hydride $\left(\mathrm{TiH}_{2}\right)$ green-compact electrodes and titanium carbide (TiC) semi-sintered electrodes had a hardness of about $2,600 \mathrm{HV}$, and a surface roughness of 10 to $13 \mu \mathrm{mRy}$. And the coating thickness of a surface layer modified with a $\mathrm{TiH}_{2}$ electrode was $12 \mu \mathrm{m}$, but the coating thickness of a surface layer modified with a TiC electrode was thinner at $2 \mu \mathrm{m}$. However the hard layers formed with $\mathrm{TiH}_{2}$ electrodes were three to four times more wear resistant and the layers formed with TiC electrodes were about ten times more wear resistant than surfaces without a hard layer.
\end{abstract}

Key words: Coating, Wear, Electrical Discharge Machining, Surface Treatment, Measurement

\section{Introduction}

Electrical discharge machines (EDMs) have the advantage that they allow die sinking for any shape regardless of the hardness of the material. So, they are widely used as the main machine in die making and for this reason EDMs are installed in almost all die making plants. Recently, trials ${ }^{(1),(2)}$ for surface modification were performed by using pulse discharges in liquids.

Generally, surface modification of dies and machine parts is performed to improve their lifetime. During die making, removal machining is performed with an already installed EDM, and after this if surface modification is possible with the same EDM, the cost and 
time required for die making could be significantly reduced. So, there are high expectations for surface modification by EDM.

In surface modification by EDM, materials intervene between the electrode and the workpiece to move the surface of the workpiece. So, it is necessary for there to be a large amount of moving materials between the electrode and the workpiece. Two methods can be classified for this purpose: a method which forms a modified film constitutes by mixing electrically conductive powders in an dielectric working fluid ${ }^{(1)}$; and a method which forms modified film by moving the electrode material to the workpiece using the impact force of an electrical discharge ${ }^{(2)}$. In the former method, the powder mixture concentration in the dielectric working fluid varies with the progress of the surface modification. For practical application it is necessary to stabilize the modified layer by keeping the powder concentration constant by installing a powder concentration sensor or powder supply unit. Therefore we studied surface modification by the latter method, which is advantageous for practical application.

In both methods a surface modified hard layer was formed and the wear resistance was shown at some test conditions. However the quantitative wear properties, which are the most important factor and used for the design data, have not been clarified. In addition, it has been almost impossible to find any documents about the effect of wear on the opposing materials.

And we quantitatively clarified the wear properties required for design data of the surface modified layers and the sliding opposing materials in order to estimate the lifetime of the surface modified actual machine.

In ordinary EDM for material removal conditions that minimize electrode wear are used, but for surface modification by EDM, conditions that allow electrode wear to increase are necessary to move the material from the electrode to the workpieces.

The wear of an electrode or workpiece is inversely proportional to the product of the thermal conductivity and the melting point ${ }^{(3)}$. For this purpose, iron and titanium have a low value and tungsten and copper have a high value. And then, in removal EDMs, copper and tungsten are used for the electrodes in many cases. In doing so, removal machining is performed on iron and steel materials with a low value of thermal conductivity and melting point while controlling the wear of the electrode.

It is considered that when an electrode is formed from powders, the coupling strength between the powders becomes smaller than the original strength of the material and the wear of the electrode is high, which allows easy machining for surface modification. Actually it has been reported that when a green-compact electrode and a sintered electrode are used, the thermal conductivity is lower than the original one for copper or aluminum, and the thermal conductivity when using a green-compact electrode is lower than when using a sintered electrode ${ }^{(4)}$.

We considered using materials with a low value of thermal conductivity multiplied by melting point to increase the wear of the electrodes and additionally compacting or sintering materials to further reduce the thermal conductivity for forming electrodes. The wear properties of surface modified layers and opposing materials were studied when surface modification was performed by EDM using easily obtainable titanium hydride $\left(\mathrm{TiH}_{2}\right)$ green-compact electrodes and titanium carbide (TiC) sintered electrodes. For sintered electrodes it was expected that the electrode would be hard wearing if the sintering was complete, therefore they were formed by lowering the sintering temperature.

\section{Experimental Procedures}

\subsection{Method of manufacturing electrode}

To manufacture $\mathrm{TiH}_{2}$ green-compact electrodes, a die was made according to the electrode size. Then $\mathrm{TiH}_{2}$ powder with a particle size of 2 to $5 \mu \mathrm{m}$ and vanadium carbide 
(VC) powder with a particle size of 5 to $8 \mu \mathrm{m}$ as an additive were blended with a weight ratio of 7:3 and mixed adequately. Then the powder was pressed into the die mold and formed with a pressure of $490.5 \mathrm{MPa}$. After this the electrode was formed to $60 \times 60 \times 15$ $(\mathrm{mm})$ with wire EDM to produce an electrode.

To manufacture TiC sintered electrodes, a die was made according to the electrode size. Then TiC powder with a particle size of 2 to $5 \mu \mathrm{m}$ was pressed into the die mold and formed with a pressure of $98.1 \mathrm{MPa}$. After that the die was kept in a furnace at a constant temperature of $1173 \mathrm{~K}$ for one hour for sintering. This sintering was not complete, because the contacting parts of the particles were liquidized and stopped at the stage of partial sintering. This was equivalent to intermediate forming called semi-sintered. After this the electrode was formed to $60 \times 60 \times 15(\mathrm{~mm})$ with wire EDM to produce an electrode.

\subsection{Electrical discharge machining conditions}

In EDM, three items, the discharge current, pulse duration and pulse interval are control parameters. It has been reported that the way to increase the wear of an electrode is to decrease the pulse duration with the electrode polarity being plus or to increase the pulse duration with the electrode polarity being minus ${ }^{(5)}$. For ordinary removal machining, the pulse duration is often increased with the electrode polarity being plus to reduce the wear of the electrode. The time and cost of producing dies and machine parts can be greatly reduced when the same EDM is used as the main plant machine in die making and surface modification. Considering future EDMs which will allow continuous machining from removal to deposition it is not preferable for users to greatly change the pulse duration according to removal or deposition.

We decided to use the pulse duration at the same level of removal machining with the electrode polarity being minus. A discharge current of $8 \mathrm{~A}$, a pulse duration of $8 \mu \mathrm{s}$ and a pulse interval of $128 \mu$ s were used as machining conditions based on a square wave pulse current using a transistor circuit. A kerosene type dielectric working fluid was used.

\subsection{Experimental method}

A ball-on-disk wear tester was used. The disk specimen had a diameter of $40 \mathrm{~mm}$ at the sliding section and the load was applied by a dead weight.

For the ball specimen, we used a commercially available steel ball bearing (SUS440C) without surface modification that had a diameter of 5/16 inch (about $7.9 \mathrm{~mm}$ ) which was quenched and tempered. For the disk specimen, stainless steel (SUS440C) measuring 50 $\mathrm{mm}$ in diameter and $8 \mathrm{~mm}$ thick was used considering the application for machine element parts.

For the disk specimen, considering the wide range of applications, a surface that could only be formed by machining was employed. Moreover, the disk specimen was surface treated by EDM using an electrode face of $60 \times 15(\mathrm{~mm})$. For comparison an untreated material without surface modification was prepared. The Vickers hardness (measuring load of $0.98 \mathrm{~N}$ ) of the disk specimen before surface treatment was $667 \mathrm{HV}$ and the surface roughness (max. height) was $2.0 \mu \mathrm{mRy}$. The Vickers hardness (measuring load of $0.98 \mathrm{~N}$ ) of the ball specimen was $710 \mathrm{HV}$.

To obtain the most appropriate machining conditions for the surface modified hard layer, several kinds of workpiece modified at a predetermined time were prepared in the same way without scanning using an electrode face of $60 \times 15(\mathrm{~mm})$. Then during machining the coating thickness of the surface modified layer and its hardness were measured.

Table 1 shows the wear test conditions. In Case 1, the sliding speed was $0.5 \mathrm{~m} / \mathrm{s}$ and the load was 9.8 $\mathrm{N}$ and these conditions were determined as standard. In Case 2, the sliding speed was doubled and in Case 3 the load was doubled. Two kinds of specimen, one whose 
surface was modified and one whose surface was not treated, were tested. Since the wear properties when not using lubricant is significantly affected by atmospheric conditions, the tester was set up in a room with constant temperature and humidity, during testing an ambient temperature of $293 \mathrm{~K}$ and humidity of $40 \%$ were maintained. Ball and disk specimens were replaced with new ones for each test. The tests were suspended at regular intervals, and were analyzed whether titanium remained on the worn surface of the modified disk specimen using electron probe micro analyzer (EPMA). When titanium was not detected the test was finished. The untreated disk specimens were tested at the same time as the surface modified specimens. The tests were carried out three times under the same conditions. The wear amount of the disk specimen was obtained by calculating the worn area of the cross-section profile of the surface roughness tester. The wear amount of the ball specimen was obtained by calculating the worn volume through microscope observation of the worn area.

Table 1 Test conditions

\begin{tabular}{|c|c|c|}
\hline Case & Sliding speed $(\mathrm{m} / \mathrm{s})$ & Load $(\mathrm{N})$ \\
\hline Case 1 & 0.5 & 9.8 \\
\hline Case 2 & 1.0 & 9.8 \\
\hline Case 3 & 0.5 & 19.6 \\
\hline
\end{tabular}

3. Results and Discussion

\subsection{Coating thickness and hardness of surface layer modified with $\mathrm{TiH}_{2}$ green-compact electrode}

Figures 1 and 2 show changes of the coating thickness of the surface modified layer and its hardness with the passage of machining time respectively. The mean Vickers hardness of the surface modified layer was obtained by measuring five points in the cross-sectional direction with a measuring load of $0.98 \mathrm{~N}$. When the machining time was approximately 100 seconds, measurement was not possible as the thickness of the surface modified layer was thin and therefore the indentation during the Vickers hardness measurement was deeper than the coating thickness.

Figure 1 shows that the coating thickness increased in proportion to the passage of time until the machining time reached approximately 1,000 seconds and after that the deposition speed of the surface modified layer gradually decreased.

Figure 2 shows that the hardness of the surface modified layer increased up to the level of 2,600 $\mathrm{HV}$ at the about 2,000 seconds of machining time, and after that the hardness gradually decreased. Generally it is said that a $\mathrm{TiC}$ layer modified by chemical vapor deposition has a hardness of 3,000 to 4,000 HV and a TiC layer modified layer by physical vapor deposition has a hardness of 3,200 to $3,800 \mathrm{HV}^{(6),(7) \text {. }}$

Figure 2 shows that the hardness of the surface modified layer is lower than those mentioned above.

There is an optimum machining time for the surface modified hard layer, and about 2,000 seconds of machining time (about 3.7 minutes per $1 \mathrm{~cm}^{2}$ of the machining area) with a coating thickness of $12 \mu \mathrm{m}$ and the maximum hardness of 2,600 $\mathrm{HV}$ is most appropriate. Therefore, for the study of wear properties of the surface modified layer we used specimens which were modified over the whole disk surface by EDM for about 2,000 seconds of machining time. 


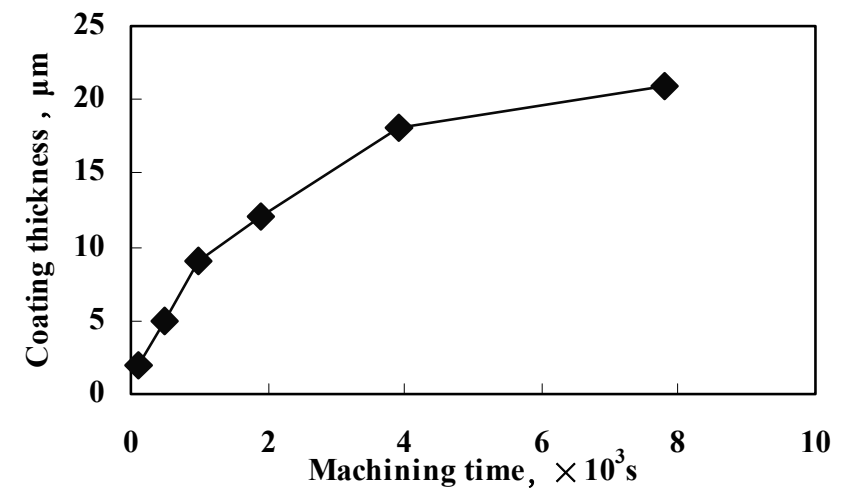

Fig.1 Relation between machining time and coating thickness in the case of $\mathrm{TiH}_{2}$ electrode

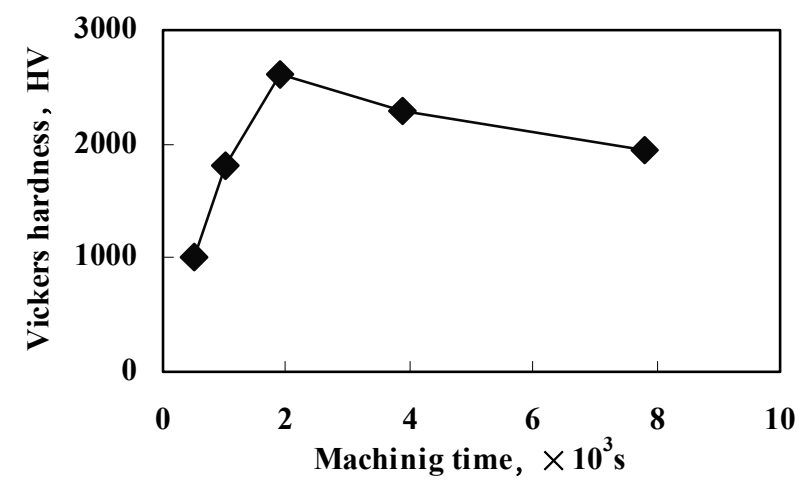

Fig.2 Relation between the machining time and Vickers hardness in the case of $\mathrm{TiH}_{2}$ electrode

\subsection{Structure of surface layer modified with $\mathrm{TiH}_{2}$ green-compact electrode}

Figure 3 shows the profile by the X-ray diffraction of the surface of modified layer. Some Fe was detected in the surface modified layer and this indicates that the surface modified layer and matrix were mixed. In the surface modified layer $\mathrm{TiC}$ and $\mathrm{VC}$ are formed. It is probable that the $\mathrm{TiC}$ was deposited as the surface modified layer after the chemical reaction of the $\mathrm{Ti}$ constituent in the electrode and the $\mathrm{C}$ in the dielectric working fluid. It is probable that the VC in the electrode is deposited in the surface modified layer as it is. It is considered that since $\mathrm{TiH}_{2}$ is thermally decomposed at about $473 \mathrm{~K}$ and mixes in the dielectric working fluid, it could not be detected.

Figure 4 shows the profile of a cross-section of the surface modified layer after about 2,000 seconds of machining time using a scanning electron microscope (SEM) and EPMA. This figure indicates that the $\mathrm{Ti}$ concentration in the surface modified layer shows the maximum value and then decreases inside the matrix. The Fe concentration of the matrix is lower near the surface and then increases inside the matrix. This also indicates that there is a border to the matrix around 10 to $13 \mu \mathrm{m}$ from the surface, which has a fairly uneven surface. Moreover, it can be seen that the porosity of about 2 to $3 \mu \mathrm{m}$ is present on the surface modified layer. The measured value of the surface roughness of a surface modified layer with a coating thickness of $12 \mu \mathrm{m}$ was 10 to $13 \mu \mathrm{mRy}$ and the surface roughness became larger because of the surface modification by EDM.

As mentioned above, in the surface layer modified by EDM the surface roughness becomes higher, but the $\mathrm{TiC}$ and $\mathrm{Fe}$ are mixed and the structure has an inclination in the depth direction from the surface. 


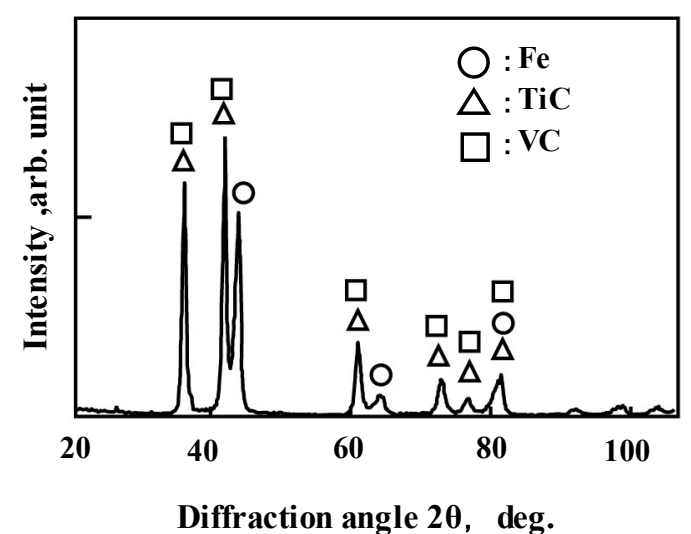

Fig. $3 \mathrm{X}$-ray diffraction pattern of coating in the case of $\mathrm{TiH}_{2}$ electrode

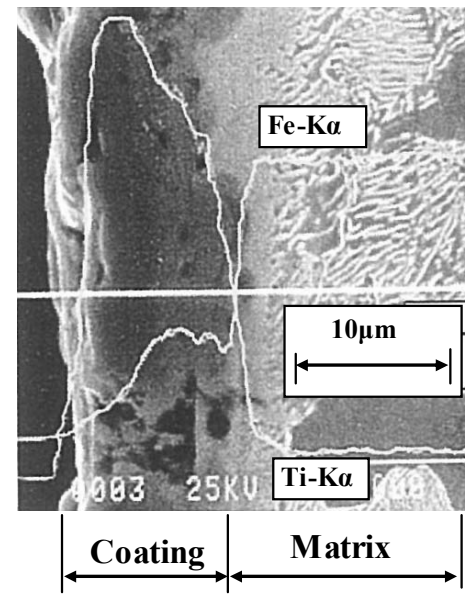

Fig.4 Characteristic X-ray intensity profiles of EPMA and cross-sectional SEM photograph of hard layer formed with EDM in the case of $\mathrm{TiH}_{2}$ electrode

\subsection{Coating thickness and hardness of surface layer modified with TiC semi-sintered electrode}

Figure 5 shows changes of the coating thickness of surface modified layer with the passage of machining time. From this figure it can be seen that the coating thickness increases in proportion to the passage of time in the early stage up to about 2,000 seconds, and after that there is hardly any deposition on the modified layer. Therefore, about 2,000 seconds is considered the most appropriate machining time. For the study of wear properties of the surface modified layer we used specimens which were modified over the whole disk surface by EDM for about 2,000 seconds of machining time (about 3.7 minutes per $1 \mathrm{~cm}^{2}$ of the machining area)

Figure 6 shows the measurement results of the dynamic hardness of surface modified layer after about 2,000 seconds of machining time. A dynamic micro-hardness meter continuously measured the indenting pressure and penetration depth of the indenter to the sample when a triangular-cone indenter with a diamond with a 115-degree ridge angle was pressed on the sample by electromagnetic force. From the measured values the hardness distribution in the depth direction can be measured by only measuring from the surface. Generally the dynamic hardness is not the same value as the Vickers hardness. Thus, the dynamic hardness around the surface modified by EDM using a $\mathrm{TiH}_{2}$ green-compact electrode was measured and it was about 3,000 DHV. The dynamic hardness value is represented by DHV below. Since the Vickers hardness of this surface modified hard layer (load $0.098 \mathrm{~N}$ ) was about 2,600 HV, it is considered that the dynamic hardness is slightly higher than the near-surface layer (under $0.1 \mu \mathrm{m}$ from the surface), which decreases rapidly up to about $1.5 \mu \mathrm{m}$ under the surface. Though it is clearly higher than that of about 3,000 
DHV it is conceivable that the surface hardness has the same level as that of the layer modified with the $\mathrm{TiH}_{2}$ green-compact electrode.

In a surface layer modified with a $\mathrm{TiH}_{2}$ green-compact electrode, the coating thickness was $12 \mu \mathrm{m}$ and hardness was 2,600 $\mathrm{HV}$ at the most appropriate machining time of about 2,000 seconds. Compared to this, it indicated that on a surface layer modified with a TiC semi-sintered electrode the coating hardness was the same value at the same machining time, but the coating thickness was about $2 \mu \mathrm{m}$.

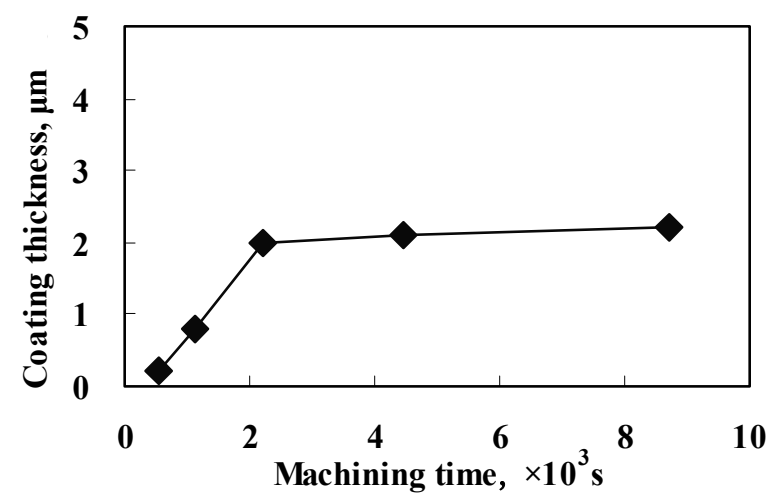

Fig.5 Relation between machining time and coating thickness in the case of TiC electrode

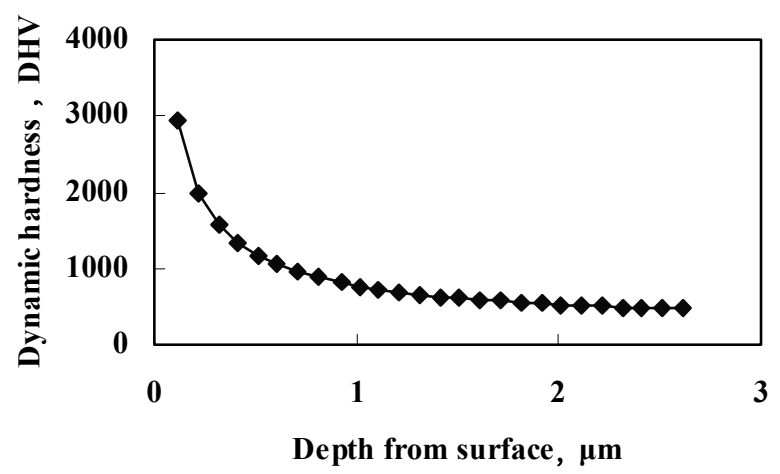

Fig.6 Relation between depth from surface and dynamic hardness in the case of TiC electrode

\subsection{Structure of surface layer modified with TiC semi-sintered electrode}

Figure 7 shows the SEM and EPMA profiles of cross-section of the surface modified layer. From this figure it can be seen that the structure of the modified layer is almost without porosity inside though some contrasting marks indicate an uneven constituent can be observed. It also can be seen that the Fe concentration of the main constituent of the matrix decreases in the area from the matrix to the surface. Also, it can be seen that the Ti concentration increases towards the surface with an inclination. The structure of the modified layer is clearly different from that of the matrix around the border to the matrix, and it is assumed that the modified layer is a heat-affected layer. It is probable that the surface modified layer is composed of a hard layer with an inclined property and a heat-affected layer.

Figure 8 shows the $\mathrm{X}$-ray profile of the surface modified layer. From this figure it can be seen that cementite $\left(\mathrm{Fe}_{3} \mathrm{C}\right)$, which may be material generated by the reaction of the $\mathrm{Fe}$ of the matrix and the $\mathrm{C}$ in the dielectric working fluid, and can be observed in the surface modified layer. The TiC shows a clear peak. The surface roughness of the modified layer 
with a coating thickness of $2 \mu \mathrm{m}$ was measured and it was 10 to $13 \mu \mathrm{mRy}$ which is almost the same as the surface layer modified with a $\mathrm{TiH}_{2}$ green-compact electrode. The surface roughness became larger due to the surface modification by EDM.

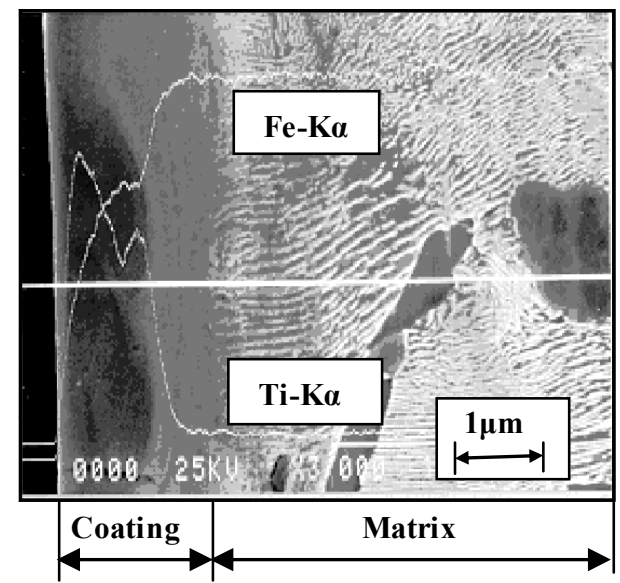

Fig.7 Characteristic X-ray intensity profiles of EPMA and cross-sectional SEM photograph of modified layer in the case of $\mathrm{TiC}$ electrode

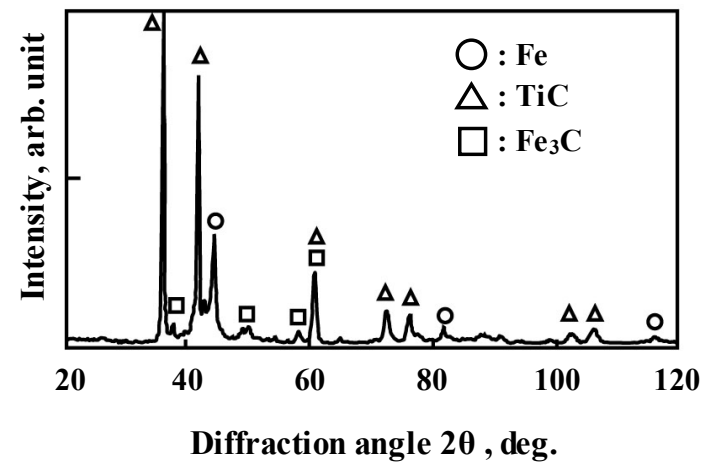

Fig. 8 X-ray diffraction pattern of coating in the case of TiC electrode

\subsection{Wear properties of surface modified layers}

Figures 9 and 10 show the wear rates of the surface modified layers and opposing materials respectively. Since the wear rates varied a little, the tests were carried out three times, but only the mean values are shown. During the tests, the different parts of the surface modified layer slide, but for the opposing materials the same part always slides. For this reason, the wear rate of the opposing materials apparently tends to become high.

From Fig. 9 it can be seen that when sliding speeds and loads in the range of the tests are used there is almost no change in the wear rate of no-coating SUS440C material. In Case 1 using a sliding speed of $0.5 \mathrm{~m} / \mathrm{s}$ and a load of $9.8 \mathrm{~N}$, the wear rate of the surface layer modified by a $\mathrm{TiH}_{2}$ green-compact electrode decreases to about $1 / 3$ to $1 / 4$ compared to no-coating SUS440C material. This shows the effect of wear resistance due to surface modification. However, in Case 2 using double the sliding speed or Case 3 using double the load, the wear rates of the surface modified layers increase. In particular, it can be seen that in Case 3 the wear rate of the surface modified layer is almost the same as that of no-coating SUS440C material.

Also the wear rate of a surface layer modified with a TiC semi-sintered electrode decreases to under 1/10 under all conditions compared to that of no-coating SUS440C material when the sliding speed and load in the range of the tests are used.

All of these reveal that a surface layer modified using a $\mathrm{TiH}_{2}$ green-compact electrode 
shows three to four times the wear resistance at a relatively low sliding speed such as 0.5 $\mathrm{m} / \mathrm{s}$ and a low load such as $9.8 \mathrm{~N}$, but looses the wear resistance effect at the double sliding speed of $1.0 \mathrm{~m} / \mathrm{s}$ or the double load of $19.6 \mathrm{~N}$. It also indicates that the surface modified layer does not show wear resistance due to an increase of load, but rather to an increase of sliding speed. A surface layer modified using semi-sintered TiC enables the wear resistance to increase more than ten times without depending on the sliding speed.

From Fig. 10 it can be found that when the sliding speed and load in the range of the tests used the wear rate of no-coating SUS440C material hardly changes.

When a surface of the disk specimen is modified using a $\mathrm{TiH}_{2}$ green-compact electrode, it can be found that the wear rate of the ball specimen increases to about 1.5 times higher than the wear rate of the ball specimen between no-coating SUS440C material and no-coating SUS440C material at the sliding speed of $0.5 \mathrm{~m} / \mathrm{s}$ and the load of $9.8 \mathrm{~N}$. However, in Case 2 using double the sliding speed and in Case 3 using double the load, the wear rate of the ball specimen decreases. In particular, in Case 3 the wear rate becomes the same as between no-coating SUS440C material and no-coating SUS440C material.

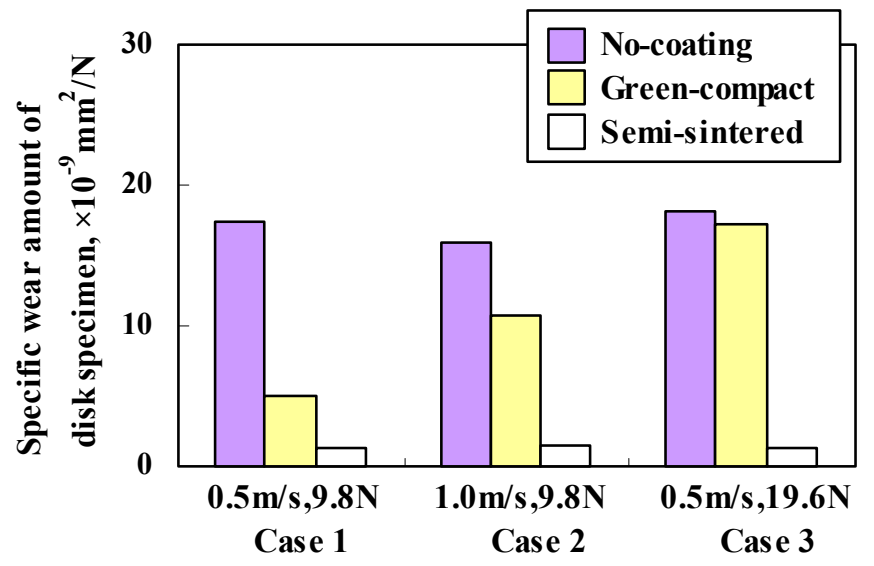

Fig.9 Wear rates of hard layer formed with EDM and no-coating

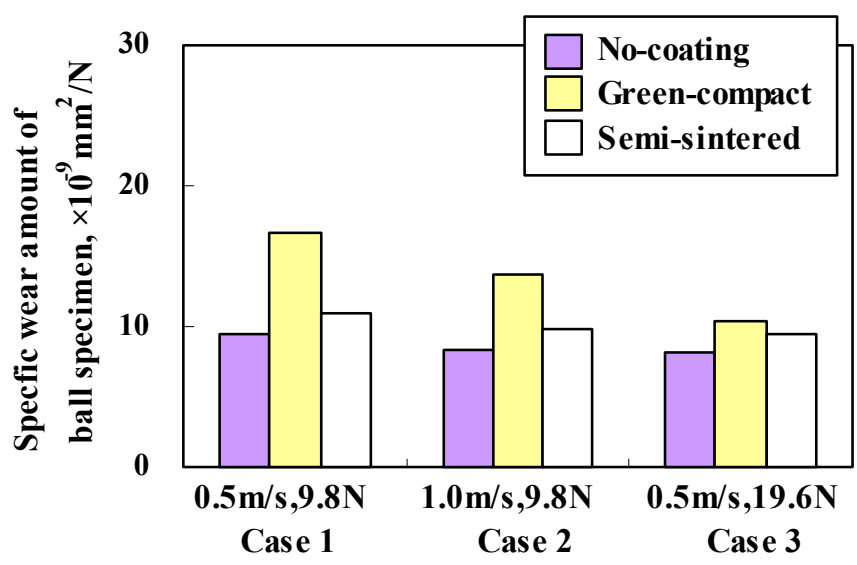

Fig.10 Wear rate of opposing materials against hard layer formed with EDM and no-coating

Furthermore when a surface is modified using a TiC semi-sintered electrode it can be seen that the wear rate of the ball specimen increases by about $10 \%$ in all conditions compared to that of no-coating SUS440C material. Therefore a surface layer modified with $\mathrm{TiH}_{2}$ green-compact electrode significantly wears the opposing materials when the modified layer has a wear resistance, but a surface layer modified with a TiC electrode hardly wears 
the opposing materials.

Figure 11 shows the cross-section SEM of the surface modified layer observed in detail. It is found that there is some porosity of about 5 to $10 \mu \mathrm{m}$ when a $\mathrm{TiH}_{2}$ green-compact electrode is used for surface modification. This porosity is considered to be attributed to hydrogen gas generated when the $\mathrm{TiH}_{2}$ is thermally decomposed.

Therefore when a $\mathrm{TiH}_{2}$ green-compact electrode is used, the surface modified layer is considered to have not-enough strength, and the wear resistance of the surface modified layer decreases under the conditions of high sliding speed and load. Many TiC wear particles are generated from the disk specimen, and the opposing material is considered to be worn by these hard wear particles between the disk specimen and the ball specimen.

Furthermore, for the TiC electrode, since the structure of the surface modified layer has little porosity, it is considered that the high wear resistance can be shown when the sliding speed and load in the range of the tests are used.

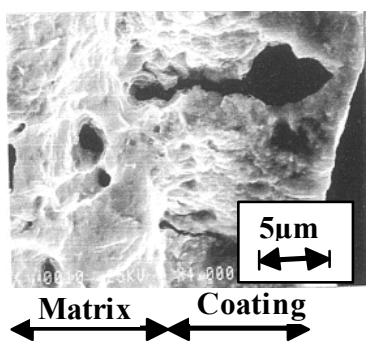

(a) $\mathrm{TiH}_{2}$ gre en compact

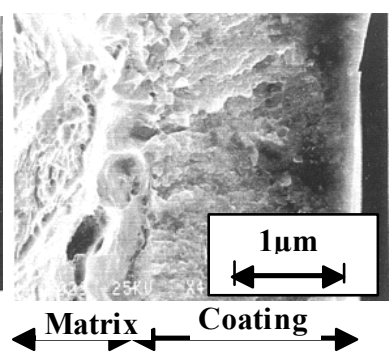

(b) TiC semi-sintered

Fig.11 Cross-sectional SEM photograph of hard layer formed with EDM

\section{Conclusions}

We studied the wear properties of surface modified hard layers using EDM with $\mathrm{TiH}_{2}$ green-compact electrodes and $\mathrm{TiC}$ semi-sintered electrodes using a ball-on-disk wear tester using balls $5 / 16$ inch diameter and circular disks made of SUS440C. As a result, the following results were obtained.

(1) Surface layers modified with both $\mathrm{TiH}_{2}$ green-compact electrodes and $\mathrm{TiC}$ semi-sintered electrodes have an inclined structure from the surface in the depth direction and have a hardness of about 2,600 HV, and a surface roughness of 10 to $13 \mu \mathrm{mRy}$.

(2) The coating thickness of a surface layer modified with a $\mathrm{TiH}_{2}$ green-compact electrode is $12 \mu \mathrm{m}$, but the coating thickness of a surface layer modified with a TiC semi-sintered electrode is thinner at $2 \mu \mathrm{m}$.

(3) A surface layer modified with a $\mathrm{TiH}_{2}$ green-compact electrode has about three to four times more wear resistance than a surface without a hard layer when the sliding speed and load are low.

(4) A surface layer modified with a TiC semi-sintered electrode has about ten times more wear resistance than a surface without a hard layer.

(5) A surface layer modified with a $\mathrm{TiH}_{2}$ green-compact electrode wears the opposing material, however a surface layer modified with a $\mathrm{TiC}$ semi-sintered electrode hardly wears the opposing material.

\section{References}

(1) Satsuta, T., Hirai, K. and Yoshizawa, M., Surface Modification Using EDM with Power Suspended Dielectric, J. of Society of Electrical-Machining Engineers, Vol.34, No.75(2000), pp.22-29(in Japanese).

(2) Goto, A., Moro, T., Matsukawa, K., Akiyoshi, M., Saito, N. and Mohri, T., Development of Electrical Discharge Coating Method, 13th Proc. Int. Smp. for Electromaching, Vol.1, 
No.1(2001), pp581-588.

(3) Suzuki, M., Mohri, T., Saito, T. and Takezawa, H., A Study on the Electrode Wear in Electrical Discharge Machining - Macroscopic observation of Removal Phenomena -, J. of Society of Electrical-Machining Engineers, Vol.26, No.52(1992), pp.47-55(in Japanese).

(4) Mohri, T., Saito. N., Tsunekawa, Y., Momiyama, H. and Miyagawa, A., Surface Modification by Electrical Discharge Machining - Composite Electrode Method -, J. of Society for Precision Engineering, Vol.59, No.4(1993), pp.625-630(in Japanese).

(5) Mohri, T. and Saito. N., Surface Modification by Electrical Discharge Machining, J. of Society for Precision Engineering, Vol.64, No.12(1998), pp.1715-1718(in Japanese).

(6) Kawana, A., Recent Trend of PVD Technology, J. of Japanese Society of Tribologists, Vol.52, No.1(2007), pp.10-15(in Japanese).

(7) Ogawa, J., Recent Trend of CVD Technology, J. of Japanese Society of Tribologists, Vol.52, No.1(2007), pp.16-21(in Japanese). 